REFERENCES:

[1] Graneheim UH, Lindgren BM and Lundman B. Methodological challenges in qualitative content analysis: A discussion paper. Nurse education today. 2017; 56: 29-34.

Disclosure of Interests: None declared

DOI: 10.1136/annrheumdis-2019-eular.3692

\section{FRI0730-HPR CAROTID ATHEROSCLEROSIS AND CARDIOVASCULAR RISK FACTORS IN FEMALES WITH SYSTEMIC LUPUS ERYTHEMATOSUS}

Oksana Sirenko ${ }^{1}$, Olexandr Kuryata ${ }^{1}$, Tetyana Lysunets ${ }^{2}{ }^{1}$ SE Dnipropetrovsk medical academy, Dnipro, Ukraine; ${ }^{2}$ Dnipropetrovsk regional hospital after Mechnikov, Dnipro, Ukraine

Background: Pts with systemic lupus erythematosus (SLE) have an increased risk for cardiovascular diseases (CVD) that cannot be explained by traditional risk factors only. Its relevant to search novel cardiovascular risk markers in those pts.

Objectives: We aimed to evaluate carotid atherosclerosis presence in females with SLE and its relationship with traditional and nontraditional cardiovascular risk factors.

Methods: 52 females with low-activity SLE (the median age - 48.2 [41.8; $52.9]$ years, the median duration of SLE $89.4[68.9 ; 101.5]$ month) without verificated coronary artery disease were enrolled. Control group included 30 pts without SLE compared by risk factors profile. The cardiovascular risk was calculated using SCORE. The total cholesterol (TC), lipoproteins, triglycerides (TG) were measured in the blood. Carotid ultrasound, endothelial-dependent flow mediated vasodilatation (EDVD) by D. Celermajer method were performed. In all pts was calculated body mass index (BMI) and measured blood pressure (BP). All pts received steroid therapy.

Results: High levels of TC, LDL and TG were in $55.8 \%, 61.5 \%$ and $25 \%$ of pts with SLE (the median levels $5.9[5.2 ; 6.4] \mathrm{mmol} / \mathrm{l}, 4.1[3.7$; 4.6] $\mathrm{mmol} / \mathrm{l}$ and $1.8[1.3 ; 2.4] \mathrm{mmol} / \mathrm{l}$ respectively). The obesity and hypertension were estimated in $51.9 \%$ and $63.5 \%$ respectively (median BMI - $31.6[28.4 ; 33.2] \mathrm{kg} / \mathrm{m}^{2}$, median systolic BP - 154,2 [138.4 162.3] $\mathrm{mm} \mathrm{Hg}$, median diastolic BP - 90.2 [82.4; 93.7] mm Hg). EDVD was impaired in $32.6 \%$ pts with SLE and $16.7 \%$ control pts $(p<0.05)$. Carotid atherosclerosis was established in $41(78.8 \%)$ pts with SLE and $48(54 \%)$ control group pts $(p<0.05)$. The majority of pts with SLE have stable carotid atherosclerotic plaques - $32(61.5 \%)$, unstable plaques - 6 $(11.5 \%)$ pts, in control group - $10(33.3 \%)$ and $2(6.7 \%)$ pts respectively. In the same time the median cardiovascular level matched by SCORE was $2.1[1.5 ; 2.9] \%$ in females with SLE, in control group - $1.8[1.3$ $2.5] \% \quad(p>0.05)$. The presence of carotid atherosclerotic plaques in females with low-activity SLE was associated with endothelial dysfunction $(\mathrm{OR}=2.5, \mathrm{p}=0.002)$, obesity $(\mathrm{OR}=1.5, \mathrm{p}=0.004)$, duration of steroid therapy $(\mathrm{OR}=2.8, \mathrm{p}=0.0005)$.

Conclusion: Females with low-activity SLE and moderate cardiovascular risk level are characterized by high frequency of carotid atherosclerosis. The carotid ultrasound may be useful additional tool for the evaluating of cardiovascular risk in these patients.

Disclosure of Interests: None declared

DOI: 10.1136/annrheumdis-2019-eular.2609 